\title{
Implication of Studies on Bilingualism for SLA
}

\author{
Minoo Alemi \\ Sharif University of Technology, Tehran, Iran \\ Email: alemi@sharif.ir \\ Parisa Daftarifard \\ Islamic Azad University (Research \&Science Branch), Tehran, Iran \\ Email: pdaftaryfard@yahoo.com
}

\begin{abstract}
Cognitively speaking, bilingualism has witnessed so many challenges and developments in practical and theoretical parts. The aim of this article is to describe and study bilingualism from different perspectives of social, individual, cognitive, psychological and political issues. To this end, this article will go through the following stages: What is Bilingual and Bilingual Education and Cognitive Processing? There are several factors which indicate what kind of decision (selective or nonselective) might be made. These include L2 proficiency, language intermixing, task demands, and instruction. Language intermixing refers to whether an experiment contains exclusively items that belong to one language (block presentation) or items from two languages (mixed presentation). Therefore, (1) lexical codes from different languages are activated in parallel on the basis of an input string; (2) selection of the lexical candidate that is identified appears to take place rather late in the recognition process; and (3) several factors affect the ultimately arising result patterns, the most important of which are a participant's L2 proficiency level, the requirements of task, and the blocked or mixed presentation of items from different languages.
\end{abstract}

Index Terms — bilingualism, bilingual education, cognitive processing

\section{INTRODUCTION}

There has been a universal tendency to examine bilingualism from a dichotomous perspective; i.e., coordinate vs. compound bilingualism (Weinreich 1953 cited in Ellis, 1994), early vs. late bilingualism (Lambert 1981 cited in Cook, 2001), simultaneous vs. successive bilingualism (McLaughlin 1985 cited in Ellis, 1994), additive vs. subtractive bilingualism (Lambert 1974 cited in Ellis, 1994), elite vs. folk bilingualism (Skutnabb-Kangas 1981), integration vs. assimilation, and separation vs. marginalization bilingualism (Cook, 2001). Such distinctions are made in reference to certain aspects of either individuals or social groups. For example, Cook (2001, p. 152) described compound and coordinate bilinguals as those "who link the two languages in their minds, or keep them apart respectively." However, the dichotomous distinction between additive vs. subtractive bilingualism refers to the social aspect of language, whereas in additive the individual would like to add to his or her native language the cultural aspect of second language. In subtractive, learners feel that learning a new language threatens what they have already gained for themselves. Assimilation bilingualism refers to the eventual dying out of the first language, while integration refers to a multilingual state where the languages exist alongside each other in harmony. Also, separation bilingualism refers to the state that different languages are spoken in physically separate regions, while marginalization refers to the state where neither native nor target culture and language are valued.

No single definition of individual bilingualism is broad enough to cover all instances of individuals who are called "bilingual." The range can extend from native-like control of two or more languages, to possessing minimal communicative skills in a second or foreign language. The former will exclude most individuals and create a new definitional problem of what native-like control of a language means. Most experts in the field prefer the latter as the beginning point from which a variety of bilingual skills can develop, including biliteracy (Baker, 2002; Faltis, 2002). This is true for societal bilingualism: While socially and politically a person is called monolingual, linguistically and cognitively speaking the same person is called bilingual through the assimilation process, e.g., Kurdish language and Kurds in Iran.

Cognitively speaking, bilingualism has witnessed many challenges and developments practically and theoretically. For example, in the realm of word representation, comprehension, and production, literature has witnessed a dramatic change in its paradigms. At one time, development of the bilingual lexicon was delineated in the "word association model," later within the concept of mediation model and now is described and explained within the revised hierarchical model (Kroll, Michael, Tokowicz, and Dufour, 2006; Kroll and Dijkstra, 2002; Kroll and Tokowicz, 2001; Sunderman and Kroll, 2006). The aim of this article is to describe and study bilingualism from different perspectives of social, individual, cognitive, psychological and political issues. To this end, this article will go through the following stages:

What is Bilingual and Bilingual Education;

Cognitive Processing 


\section{WHAT IS BILINGUAL AND BILINGUAL EDUCATION}

Understanding bilingual education requires a series of multidisciplinary perspectives (Baker, 2002). This includes pedagogic, language planning, political, economic, public (opinion) (Krashen, 1999 cited in Baker, 2002), sociolinguistic (Mckay and Hornberger, 1996 cited in Baker, 2002), psychological (Baker, 1996, cited in Baker, 2002), historical (Kloss, 1998 cited in Baker, 2002), and national perspectives (Cummins and Corson, 1997). The complexity of bilingual education compounds when one notices the componentiality of pedagogy which can be divided into teaching methodology, learning strategies, curriculum resourcing, teacher training, and school organization.

The first perspective is the viewpoint of language planners. Language planning gained in it importance when issues such as language maintenance, revitalization, and reversal of language shift came into notice (Baker, 2002). According to Baker (2002), for a language to survive, it should be loved and lived. Therefore, a minority's language which is not used in the community in television, school, and radio would be in danger of dying. According to Baker (2002, p.230), there are four major priorities that are associated with the survival and strengthening of a minority language: "Language reproduction in the family"-when families do not use the minority language at home, language will decline; "Language production from preschool education through formal schooling to adult education"-most education is done through standard language; "using the minority language for economic purpose"-when there is no real value in the employment market for minority language; "social, cultural, and leisure participation through the minority language." As far as cultural and social aspects are concerned, minority language use is encouraged when it is culturally valued and when it is used enjoyably in cultural and leisure activities. Literacy is also an important matter in language survival; "any language without literacy in this century may be in grave danger of dying out" (Baker, 2002, p. 232). Elsewhere, Faltis (2002) argues that national as well as local views on the use of bilingualism or multilingualism have powerful effects on the ways the language or languages are distributed in educational and social contexts. Patriotism, for example, is considered a main reason to hinder the use of Multilanguage in the schools in the United States. As Faltis and Hudelson (1998 cited in Faltis, 2002) wrote, the purpose of education in the United States is "transitional" in the sense that it moves students from their native language to English as quickly as possible.

An alternative approach to bilingual education is "dual language bilingual education" (Lindholm and Molina, 2000 cited in Faltis, 2002) or "two-way immersion or maintenance bilingual programs" (Faltis and Hudelson, 1998 cited in Faltis, 2002). In this type of education, two different language groups are enrolled in a school to learn through each others' native language. The purposes of such an educational program are "(1) learn the language of the others, (2) achieve academically in both languages, and (3) come to appreciate each others' languages and cultures" (Faltis, 2002, p. 279). Although applauded as a valuable goal, non-dominant language even in such programs is less valued in schools. For example, although English speakers learning French in French immersion schools were praised for their efforts in learning French, they know that learning French for them was not a social goal but an instrumental one. Therefore, minority children in dual language programs are expected to acquire high levels of English, the language of power, business, and education.

There are three key limitations to the language planning perspective of bilingual education: (1) bilingual education for the sake of language not the child, (2) having a limited view of the functions and purposes of education, and (3) being overly optimistic in revitalizing a language minority. Although educationalists argue for bilingual education from different perspectives, they agree that bilingual education displays eight merits over monolingual education. These are: (1)developing more than one language proficiency, children would have more options in patterns of communication; (2)bilingual education develops a broader enculturation; (3)bilingual education can easily lead to bi-literacy or multiliteracy; (4)bilingual children can enjoy certain cognitive benefits; (5)bilingual children may enjoy high esteem; (6)curriculum achievement increases through bilingual education; (7)bilingual education has an important role in establishing the security of identity at a local, regional, and national level; and (8)bilingualism has an advantage in securing jobs.

Bilingual education, however, faces several limitations and disadvantages. First, according to Cummins (2000 cited in Baker, 2002), bilingual education may not guarantee effective schooling. Second, the type and use and register related issues in bilingual education are a problem. And third, language learning in bilingual education may stop at the school gates.

Politics also has played an important role in bilingual education research. Whenever bilingual education exists, politics is close by. Behind bilingual education there are always expressions of political ideology, tides of political change, and the political initiative. The existence of LEP (limited English proficiency) between 1978 and 2000 in California indicates the importance of the issue in political matter in the United States. Cummins (1999 cited in Baker, 2002) also believes that different theories in SLA, such as thresholds, interdependence, and conversational and academic language proficiency, are supported by research and answer a range of policy issues.

\section{COMMUNITY FORCES AS CONTEXT}

How minority language and bilingual communities perceive and respond to their past and present treatment in schools constitutes what Ogbu (1983 as cited in Faltis, 2002) refers to as "community forces." The concept would indicate the extent to which bilingual children can succeed in school. Ogbu argues that language-minority groups who 
were originally conquered, colonized, or enslaved develop cultural models or belief systems to form their identities and guide their actions in society. Such systems work through folk theories, and intra-group social capital. Community members begin to form belief systems about the value of their ways of doing things, including language learning and use, as compared to the dominant ways of behaving. The degree to which language-minority communities trust the school and school staffs also contributes to community forces as a context for bilingualism development in schools.

\section{Pedagogical ORIEntations AND TEACHER ABilities as CONTEXT}

Pedagogical orientations and teacher abilities in all levels of education both reflect societal and community forces, and create context in which bilingual children are prepared for society in school (Edelsky, 1991 cited in Faltis, 2002). This includes a variety of factors for administrators, school board members, and teachers as well as members of the dominant society. Administrators and teachers who see the language minority deviated from their native language and culture believe that providing students with too much exposure to their native language would be a waste of their time and energy. Therefore, learners in such an area will be minimally supported in their native language. This is called the assimilationist perspective. On the other hand, in a context where administrators and the school faculty advocate for cultural pluralism, the additive approach to bilingualism, the bilinguals will have the opportunity to develop into highly biliterate individuals.

Pedagogy defines how a teacher understands the nature of teaching and learning and his or her theoretical commitments to practices in the classroom. However, it might differ in orientation. Teachers are either transactionaloriented or transitional-oriented. Broadly speaking, transactional-oriented bilingual teachers rely on a holistic approach to teaching and learning. In their approach, teaching is a matter of moving students from literacy practices to multiple literacy practices including knowledge about how language works. From this point of view, language acquisition and learning takes place through participation in social activities in which learners use many forms and functions of language. Learners in such a context will develop into bilinguals who can manage to work with two systems effectively for multiple academic purposes. Therefore, learners might use their native language even if they are proficient in a second language. They are not pushed into using a second language at all. On the other hand, transmission-oriented bilingual teachers view teaching and learning as a matter of giving learners the language and knowledge they need to succeed on tests. In such a context, learners only pay attention to the knowledge and the content information which is broken into bits and pieces they need to master. These learners see learning as an activity on worksheets, homework, and standardized tests. Therefore, biliteracy is presented as a set of skills in two languages, but native language skills are valued only to the extent that they enable students to perform well on dominant-language standardized tests.

Another way of differentiating the contexts is related to teachers' pedagogical orientation. There are two different types of teachers in this respect. One group of teachers translate much of what they say and write from one language to the other to ensure that all learners understand and to move the lesson along. Although it seems that both languages are used in this context, learners would not pay attention to the dominant language (Wong Fillmore and Valadez, 1986 cited in Faltis, 2002). Another context is where teachers use both languages interchangeably. Such teachers are highly supportive of additive bilingualism. However, students in such contexts see their native language as a bridge to English.

\section{COGNITIVE PROCESSING}

De Bot (2002) explains bilingual cognitive process through mechanisms of language "selection" and language "separation." He believed that such mechanisms are applicable both in full bilinguals and in incipient learners of second language. He stated that code-switching (henceforth CS) is a source of data through which to study these mechanisms. CS is a unique process in which various layers of processing more than one language are involved. One of the famous models in code-switching is Levelt's speaking model (1989 cited in De Bot, 2002). The model delineates the speaking process through different modules of (1) the conceptualizer, (2) the formulator, and (3) the articulator.

In the conceptualizer module, communicative intentions are translated into messages that can function as an input to the speech production system. According to Levelt (1989 cited in De Bot, 2002), there are two planning types in processing: macroplanning and microplanning. Levelt defined macroplanning as the planning of a speech act, the selection of information to be expressed, and the linearization of that information. Microplanning refers to propositionalization of the event to be expressed, the perspective taken, and certain language-specific decisions that have an effect on the form of the message to be conveyed. The output is a "preverbal" message that consists of all the information needed by the next module, the formulator, to convert the communicative intention into speech.

The formulator converts the preverbal message into a speech plan (phonetic plan) by the selection of lexical items and the application of grammatical and phonological rules. Lexical items are composed of two parts: a lemma and the morphophonological form, or lexeme. A lemma represents the lexical entry's meaning and syntax, while a lexeme represents its morphological and phonological properties. In production, lexical items are activated by matching the meaning part of the lemma with the semantic information in the preverbal message. Lexicon information is available in two stages: first semantic activation occurs, then form activation. The lemma information of a lexical item concerns both conceptual specifications of its use, such as pragmatic and stylistic information, and (morpho-) syntactic 
information such as syntactic category and grammatical functions as well as information on syntactical encoding (number, tense, aspect, mood, case, and pitch accent).

The next module is the articulator which converts the speech plan into actual speech. The output from the formulator is processed and temporarily stored in such a way that the phonetic plan can be fed back to the speech-comprehension system and the speech can be produced at normal speed. And the last module is a speech-comprehension system connected with an auditory system. This module plays a role in two ways: the phonetic plan and overt speech are passed on to the speech-comprehension system, where mistakes can be traced. Then speech understanding is modeled as the mirror image of language production, and the lexicon is assumed to be shared by the two systems.

The Levelt model was developed for monolingual language development. To apply this model to CS, one needs to clarify to what extent the present model is capable of handling bilingual speech. According to Poulisse (1997 cited in De Bot, 2002), there are two types of code switching: motivated switches and performance switches. Motivated switches refer to deliberately switching from L2 to L1 while performance switches refers to unintentionally switching from L2 to L1.

Psycho-linguistically, CS and keeping languages apart are different aspects of the same phenomenon. Paradis (1981 cited in De Bot, 2002, p.292) has proposed the subset hypothesis, according to which "words (but also syntactic rules or phonemes) from a given language form a subset of the total inventory." This subset can be activated independently, or overlapped in the form of cognates. According to the subset hypothesis, bilingual speakers have stores for lemmas, lexemes, syntactic rules, morphophonological rules and elements, and articulatory elements. Within each of these stores there are subsets for different languages, varieties, styles, and registers.

A lemma consists of three parts: semantic specification, syntactic information, and pointer to a particular lexeme. The semantic specification refers to a set of conceptual conditions under which the lemma can be appropriately used. The syntactic information refers to the syntactic category of a lemma and its grammatical functions. Finally, the third type of information in the lemma is a pointer to a lexeme. The pointer contains the phonological specifications of a lemma and the morphological makeup. Experimental data from tip-of-the-tongue research shows that as speakers were able to retrieve a lemma, such as phonological encoding, different types of information come together, prosodic metrical and segmental information, but the speakers could not find the lexeme connected with it.

The process of lexical access happens through different stages as mentioned earlier. One important point is that these steps are serial in the sense that accessing one module should be preceded by accessing another module. This means that there is no possibility of conveying information from the conceptualizer to the formulator other than through the preverbal message. In other words, all information about language choice has to be included in some form in the preverbal message.

Another point to be mentioned is the concept of access to lemmas and lexis. Sometimes the cue values for both languages are high, because both have to get about equal access to the output system. In some cases, language turns out to be a less important cue than other semantic cues. In fact, the language cues in the preverbal message define what the system aims at. According to Levelt (1989 cited in De Bot, 2002), in speaking, the number of words produced in a given period of time can be very high, a rate of two to five words per second. This is not the case in bilinguals; reportedly, they need more time to retrieve words from memory than monolinguals (Mack, 1986 cited in De Bot, 2002). Elsewhere, Levelt (1989 cited in De Bot, 2002) mentioned that the language selection happens in a hierarchical order in the sense that activation of a lemma leads to the activation of grammatical procedures. This happens in the form of building the syntactic environment around the major categories of lemma; N, V, A, and P changed into NP, VP, AP, and PP in categorical procedure, then S-procedure, and the like. This is called procedural packages (Kempen and Hoenkamp, 1987 cited in De Bot, 2002).

\section{SWITCHING SITES}

There are several "switching sites" during the production process. At all of these switching sites, elements from a particular language can be selected (De Bot, 2002). There are different levels at which code-switching might happen. However, the literature primarily supports the theory that CS occurs with syntactic and morphological constraints. These possible levels of CS are briefly described below:

1. Lemma selection: A mismatch at the conceptual level may lead to the selection of a word from another language

2. Syntactic structure activation: Nortier (1989 cited in De Bot, 2002) identified a rank order of CS sites. The rank orders show that CS most likely occurs between coordinated sentences and around adverbs, and is less likely between a subordinated and main sentence or inside prepositional phrases.

3. The selection of lexemes: Morphemes have to be combined. Sometimes a stem from one language and a bound morpheme from another language is combined.

4. The output of the phonological encoding into the metrical spell-out

5. The output of the prosody generator as input for the address frames: Lexemes from one language combine with affix-like elements from another language.

6. The transition from address frames to phonological words: Use sounds and elements from one language in a phonological structure from another language. 
Elsewhere, Kroll, and Dijkstra (2002, p. 301) question whether "bilinguals represent words in each language in a single lexicon or in separate lexicons and whether access to the lexicon is selective or not." They mention that to answer these questions there are several assumptions that should be taken into account. The first assumption is related to the relationship between representation and the process. According to this assumption, the form and the manner of access are independent dimensions (VanHeuven, Dijkstra, and Grainger (1998 cited in Kroll, and Dijkstra 2002). The second assumption is related to the way the lexicon itself is operationalized.

\section{THE REVISED HIERARCHICAL MODEL}

The revised hierarchical model (RHM) (Kroll and Stewart, 1994 cited in Kroll and Dijkstra, 2002) captures the idea that the shift from lexical to conceptual processing will increase with increase in L2 proficiency. This means that early in acquisition, the reliance on lexical-level connections between words in the two languages provided a means for transfer (Kroll and Tokowicz, 2001; Sunderman and Kroll, 2006). As you can see in figure -1-, the connection between L2 to L1 transfer is stronger than L1 to L2 transfer during early acquisition; however, the connection between L1 and concepts is stronger than between $\mathrm{L} 2$ and the concept.

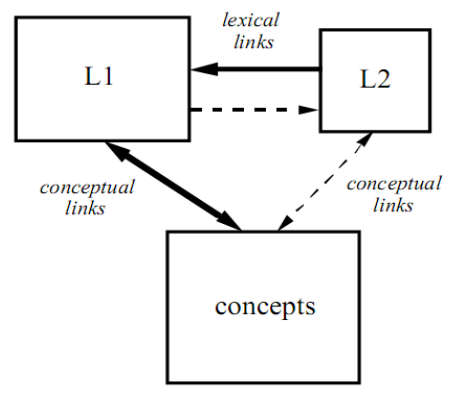

Figure 1

To test the model, Kroll and Stewart (1994 cited in Kroll and Dijkstra, 2002) examined translation performance in a group of highly fluent Dutch-English bilinguals. Two conditions were tested: Words to be translated were categorized semantically and randomly. Two types of translation were examined: forward and backward. The results suggest that forward translation from L1 to L2 was slower than backward translation from L2 to L1. The RHM assumed independent lexical representations for words in each language. There is another model which is called bilingual interactive activation model which is a computer simulation model which can account for both parallel access and asymmetrical access to words.

\section{The Bilingual InTERACTIVE ACtivation Model(BIA)}

This model is a computer model for bilingual visual word recognition that incorporates one possible proposal. It consists of a network of hierarchically organized representational units of different kinds: feature, letters, words, and language nodes. According to this model, presentation of an input letter string leads to parallel activation of several possible words (the neighborhood) irrespective of language. Later, competition takes place between items from the same and different languages though the mechanism of "lateral inhibition." The BIA model can explain the asymmetries observed in unbalanced bilinguals. Kroll, Michael, Tokowicz, and Dufour (2002) studied two groups of native English speakers, one more and one less fluent in French as their L2, as they performed word-naming and translation tasks. Learners were slower and more error-prone to name and to translate words into L2 than more fluent bilinguals. However, there was also an asymmetry in translation performance such that forward translation was slower than backward translation. Learners were also slower than fluent bilinguals to name words in English, the L1 of both groups. In another experiment, Kroll, Michael, Tokowicz, and Dufour (2002) compared the performance of native English speakers at early stages of learning French or Spanish to the performance of fluent bilinguals on the same tasks. The goal was to determine whether the apparent cost to L1 reading was a consequence of L2 learning or a reflection of differences in cognitive abilities between learners and bilinguals. Experiment 2 replicated the main features of Experiment 1 and showed that bilinguals scored higher than learners on a measure of L1 reading span, but that this difference did not account for the apparent cost to L1 naming. They consider the implications of these results for models of the developing lexicon. 


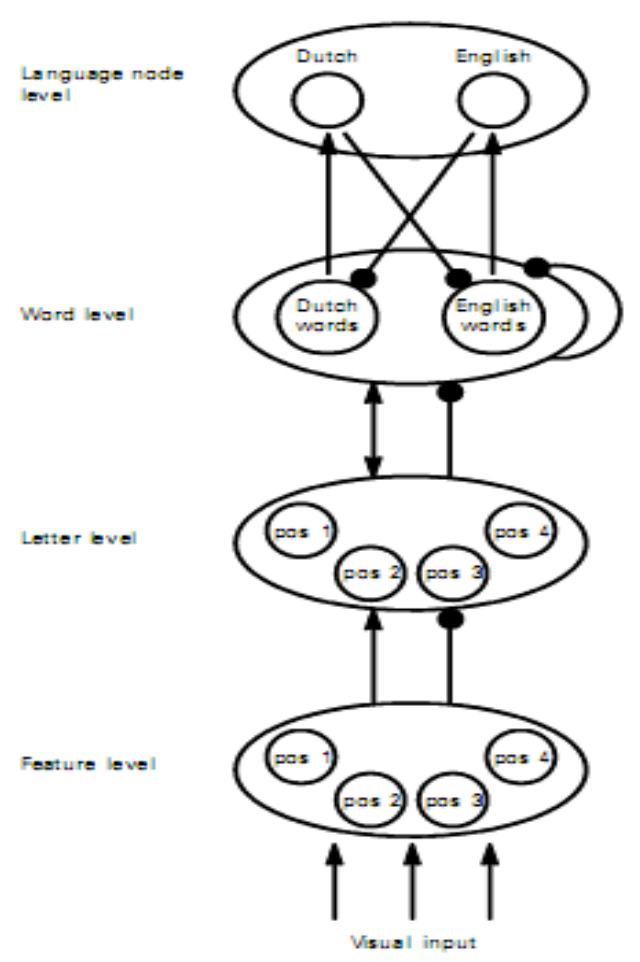

Figure 2

\section{COMPREHENSION VS. PRODUCTION IN BILINGUALS}

Different bilingual models have tried to explain the processes and the result of comprehension and production. The fact that production is linear but comprehension might not be, causes scholars to differentiate between these two (Pienemann, 2003). One of the most frequently used tasks in monolingual and bilingual research is word recognition, in which the participants are to recognize the words orthographically, semantically, or phonologically (Kroll and Dijkstra, 2002; Kroll and Tokowicz, 2001; Sunderman and Kroll, 2006). There are different studies in this respect. For example, studies on ambiguous words suggest that different meanings of these words are initially activated during recognition. Other research includes studies on homographs, and homonyms. These studies show that homographs were read slower than homonyms and control words. The result of all these studies suggests two different access views: nonselective and language selective. According to the nonselective access view, it should not matter very much whether the co-activated lexical candidates belong to the same language or to another, i.e., interlingual activation of similar words during bilingual word recognition. In contrast, a language-selective access view refers to the idea that the presented word will activate the form and meaning representations only from the language that is currently selected. Different research indicates that lexical decisions were facilitated by cross-linguistic orthographic and semantic similarity relative to control words that belong only to English.

\section{CONCLUSION}

There are several factors which indicate what kind of decision (selective or nonselective) might be made. These include L2 proficiency, language intermixing, task demands, and instruction. Language intermixing refers to whether an experiment contains exclusively items that belong to one language (block presentation) or items from two languages (mixed presentation).

Therefore, (1) lexical codes from different languages are activated in parallel on the basis of an input string; (2) selection of the lexical candidate that is identified appears to take place rather late in the recognition process; and (3) several factors affect the ultimately arising result patterns, the most important of which are a participant's L2 proficiency level, the requirements of task, and the blocked or mixed presentation of items from different languages.

The most striking similarity between comprehension and production in bilinguals is the overwhelming evidence for nonselective access to words in both languages, regardless of whether the task logically permits the language of processing to be selected in advance. In both processes, the consequences of the lower L2 and L1 proficiency are in unbalanced bilinguals.

\section{REFERENCES}


[1] Baker, C. (2002). Bilingual education. In R. B. Kaplan (Ed.), The oxford handbook of applied linguistics (pp. 229-242). Oxford: OUP

[2] Bialystok, E. (2001). Bilingualism in development: Language, literacy, and cognition. Cambridge: CUP.

[3] Cook, V. (2001). Second language learning and language teaching (3rd Ed.). New York: Arnold.

[4] Cummins, J. (1976). The influence of bilingualism on cognitive growth: A synthesis of research findings and explanatory hypotheses. Working Papers on Bilingualism, 9, 1-43.

[5] De Bot, K. (2002). Cognitive processing in bilinguals: language choice and code-switching. In R. B. Kaplan (Ed.), The oxford handbook of applied linguistics (pp. 287-300). Oxford: OUP.

[6] De Bot, K., \& Kroll, J. F. (2002). Psycholinguistics. In N. Schmitt (Ed.), An introduction to applied linguistics, (pp. 133-149). London: Arnold.

[7] Ellis, R. (1994). The study of second language acquisition. Oxford: OUP.

[8] Faltis, Ch. (2002). Contexts for becoming bilingual learners in school settings. In R. B. Kaplan (Ed.), The oxford handbook of applied linguistics (pp. 229-242). Oxford: OUP.

[9] Judith F. Kroll, A. M. B. de Groot. (2005). Handbook of bilingualism: psycholinguistic approaches. Oxford University Press.

[10] Kroll, J. F., \& Dijkstra, T. (2002). The bilingual lexicon. In R. B. Kaplan (Ed.), The oxford handbook of applied linguistics (pp. 301-321). Oxford: OUP.

[11] Kroll J. F., \& Tokowicz, N. (2001). The development of conceptual representation for words in a second language. In J. Nicol (Ed.), One mind, two languages: Bilingual language processing (pp.90-110). Malden, MA: Blackwell Publishers.

[12] Kroll, J. F., \& Sunderman, G. (2003). Cognitive processes in second language learners and bilinguals: The development of lexical and conceptual representations. In C. Doughty \& M. Long (Eds.), The handbook of second language acquisition (pp. 104129). New York: Blackwell.

[13] Lambert, W. E. (1985). Some cognitive and sociocultural consequences of being bilingual. In J. E. Alatis \& J. J. Staczek (Eds.), Perspectives on bilingualism and bilingual education (pp.55-85). Washington, DC: Georgetown University Press.

[14] Paradis, M. (1994). Neurolinguistic aspects of implicit and explicit memory: Implications for bilingualism and second language acquisition. In N. Ellis (Ed.), Implicit and explicit learning of languages (pp. 393-419). London, San Diego: Academic Press,

[15] Pienemann, M. (2003). Language processing capacity. In C. Doughty \& M. H. Long (Eds.), The handbook of second language acquisition (pp. 679-714). New York: Blackwell.

[16] Skutnabb-Kangas, Tove. (1981). Bilingualism or not. Multilingual Matters Ltd. Clevedon, England.

[17] Sunderman, G., \& Kroll, J. F. (2006). First language activation during second language lexical processing: an investigation of lexical form, meaning, and grammatical class. SSLA, 28, 387-422.

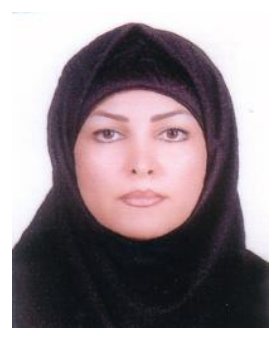

Minoo Alemi is a Ph.D. candidate of TEFL at Allameh Tabataba'i University. She is also a faculty member and vice-Dean of Education at Languages and Linguistics Department at Sharif University of Technology. She has taught English courses for over a decade at different universities in Tehran. Moreover, she has published many articles in international journals and more than ten English textbooks for GE and ESP courses.

Parisa Daftarifard is currently a PhD student at Azad University, Science and Research Branch, Tehran, Iran. She received her MA degree from Iran University of Science and Technology in 2002. Her primary research interests concerns EFL reading, testing, and second language acquisition. 